Revista de Ensino em Artes, Moda e Design

Dossiê 5

As fontes de pesquisa para moda. Uma aproximação interdisciplinar e arquivista da história da moda: pesquisa e ensino.

\title{
A MODA E O VESTUÁRIO COMO OBJETOS DE ESTUDO NA HISTÓRIA*
}

\author{
Fashion and clothing as objects of study in \\ History
}

\section{La mode et le vêtement comme objets d'étude de l'histoire}

\section{Paulo Debom ${ }^{1}$}

1 Doutor em História Política pelo PPGH-UERJ. Mestre em Ciências Sociais pelo PPCIS-UERJ. Docente dos cursos de História e de Artes Cênicas do Centro Universitário Celso Lisboa - RJ. Editor da Revista Veredas da História. Organizador e coautor do livro A História na Moda, a Moda na História, editora Alameda, 2019.

E-mail: paulodebom@gmail.com | Lattes: http://lattes.cnpq.br/5100220209026692 | Orcid: http://orcid.org/0000-0002-2041-3182

* Esse artigo trata-se de uma versão ampliada do texto O Vestuário e a Moda enquanto Fontes para o Estudo da História apresentado no XVI Encontro de História da ANPUH-Rio em 2013. 


\title{
Resumo
}

O objeto moda não ocupava uma posição de destaque na produção acadêmica na área de História. Em geral, era visto como um assunto conectado ao fútil e ao frívolo, por isso era relegado a um segundo plano. A maior parte das publicações científicas tinham por origem as áreas de comunicação, design, sociologia, antropologia, psicologia, artes, dentre outras. Embora o número de historiadores que se dedicam ao vestuário e às aparências ainda seja pequeno, esse cenário sofreu significativas alterações nas últimas duas décadas. Esse texto tem por objetivos: pensar sobre a importância da Moda para os estudos históricos; destacar a relevância dos estudos de Roland Barthes, Fernand Braudel, Daniel Roche, Gilda de Mello e Souza para a construção desse campo do conhecimento e, por fim, apontar o espaço que essa área de estudo preencheu tanto no mercado editorial quanto nos simpósios realizados em eventos acadêmicos.

Palavras-Chave: História. Moda. Historiografia.

\begin{abstract}
Fashion as an object of study did not occupy a prominent position in academic production in the fields of History. It was often seen as something connected with the futile and frivolous, so it was relegated to the background. Most of the scientific publications originated in the areas of Communication, Design, Sociology, Anthropology, Psychology, Arts, among others. Although the number of dress and appearance historians is still limited, this scenario has changed significantly over the past two decades. This article aims to: examine the importance of Fashion for historical studies; to highlight the relevance of the studies of Roland Barthes, Fernand Braudel, Daniel Roche, Gilda de Mello and Souza for the construction of this field of knowledge and lastly to point out the significance of this area of study in both editorial market and symposiums within academic events.
\end{abstract}

Keywords: History. Fashion. Historiography.

\section{Résumé}

L'objet mode n'occupait pas une place importante dans la production universitaire d'Histoire. En général, il était perçu comme un sujet connecté au futile et au frivole, étant, par cette raison, relégué au second plan. La majorité des publications scientifiques avait par origine les domaines de la communication, du design, de la sociologie, de l'anthropologie, de la psychologie, de l'art, parmi d'autres. Malgré le petit nombre d'historiens dédiés à l'habillement et aux apparences, ce scénario a souffert de transformations importantes les deux dernières décennies. Ce texte a pour buts: penser sur l'importance de la mode pour les études historiques, faire remarquer l'importance des études de Roland Barthes, Fernand Braudel, Daniel Roche, Gilda de Mello e Souza et, finalement, montrer l'espace que ce champ d'études a pris tant sur le marché éditorial quant sur les symposiums organisés dans des événements universitaires.

Mots-clés: Histoire. Mode. Historiographie. 


\title{
1 A IMPORTÂNCIA DE ROLAND BARTHES
}

A Moda ${ }^{1}$ é um objeto em geral pouco valorizado no meio acadêmico. A ideia de que pensar sobre o assunto é uma perda de tempo está ligada ao que Roland Barthes, em 1957, chamou de o mito comercial da moda (BARTHES, 2005, p. 258). Com certeza, seria leviano negar que a roupa está intimamente atrelada à cultura de consumo no Ocidente e o autor discutiu de forma brilhante o tema em seus textos. Porém, ficar preso a este ponto é algo ingênuo. Nos trajes entrecruzam-se diversos elementos simbólicos que edificam uma época. As vestes permitem leituras enviesadas que caminham pelas mais diversas esferas do pensamento, da política e da economia.

\begin{abstract}
A História da Indumentária ainda não se beneficiou da inovação dos estudos históricos que ocorreu na França há uns trinta anos: ainda está faltando toda uma perspectiva institucional da indumentária, em termos de dimensão econômica e social da História, de relações entre o vestuário e fatos de sensibilidade [...] (BARTHES, 2005, p. 258).
\end{abstract}

Os primeiros trabalhos históricos dedicados aos trajes foram escritos no século XIX. Os dois mais marcantes são de Jules-Étienne Quicherat, Histoire Du Costume en France Depuis les Temps les plus reculés jusqu'á La fin du XVIII siècle (1875); e de Albert Racinet, The Historical Encyclopedia of Costume. Tratam-se de obras que possuem rico levantamento de dados sobre as mudanças das silhuetas, mostrando de maneira descritiva como eram as formas vestimentares de diversos povos. Funcionam como uma espécie de glossário da indumentária. No entanto, carecem de reflexões que estabeleçam relações do vestir com o contexto histórico.

A virada veio nos anos 1950, com o pensador Roland Barthes. Seus estudos podem ser considerados como fundadores das pesquisas sobre Moda em diversos campos do conhecimento: Semiologia, História, Sociologia, etc. Apesar de Paris ser considerada a capital da Moda desde o século XVII, pouco se falou de relevante sobre o assunto nos meios acadêmicos franceses antes dele. De certa forma, sua produção deu à Moda o status de objeto do pensamento. Engana-se quem acredita que seu único trabalho sobre o assunto restringiu-se ao livro O Sistema da Moda, publicado pela primeira vez em 1967.

Obras como Inéditos 3: Imagem e Moda (1950-1970/2005), Elementos de Semiologia (1964/2006) e Mitologias (1957/2010) versam sobre a análise de discursos até então pouco valorizados cientificamente, como filmes, propagandas, alimentação e Moda. Esses escritos deram um frescor ao pensamento sobre os fenômenos sociais, visto que abriram uma trilha ímpar sobre o processo de construção, desconstrução e reconstrução de sentidos em objetos que até então eram desvalorizados. Alguns de seus contemporâneos viam em seus trabalhos uma traição ao pensamento científico. Entretanto, ao se fazer um panorama de sua vida, percebe-se que tinha paixão pelo desvio e percebia nas linhas sinuosas os melhores caminhos para se pensar o ser humano.

Percebe-se que seu mais famoso livro, O Sistema da Moda, escrito entre os anos 1950 e 1960, apresenta linhas de difícil compreensão, mesmo para aqueles que já estão inseridos em seu universo por meio de outras obras. Uma leitura árdua que, em um primeiro momento, não lembra aquele homem encantado pela provocação e pelos fluxos da paixão. O livro era sua tese de doutorado, orientada inicialmente por Claude

\footnotetext{
1 A palavra Moda é escrita com letra maiúscula para se referir ao conceito de Moda enquanto algo que não se restringe às roupas; mas sim à postura e a visão de mundo. Desta forma, o presente texto parte do mesmo princípio de Roland Barthes em O Sistema da Moda (2009, p.19): "Escreveremos Moda como maiúscula[...] para podermos manter a oposição entre a Moda e uma moda".
} 
Lévi-Strauss e, depois, por André Martinet, que nunca foi defendida. Talvez, os rigores impostos pela escrita acadêmica tenham gerado linhas tão esquemáticas. Quiçá a autocobrança por parte do autor em realizar um trabalho no qual conseguisse conjugar os pressupostos da linguística de Saussure e a metodologia estruturalista de Lévi-Strauss, sejam as razões para o texto ser considerado por alguns como indecifrável. No entanto, ao se mergulhar com real vontade na obra, rompendo as barreiras iniciais, percebe-se que, o Barthes poético, ali se encontra.

Nos discursos do universo das roupas, o indivíduo se coloca no mundo através de seu corpo vestido. Os trajes que o cobrem são escolhas ou imposições que se constituem em discursos que formam seu visual e, ao mesmo tempo, dialogam com os outros. Desta forma, a Moda forja o sujeito através da construção de uma marca identitária que o relaciona com todos àqueles que o cercam.

Em uma visão superficial, uma roupa não passaria apenas de um traje que cobre o corpo. Seria apenas uma peça ou combinações delas, que as pessoas usam para ficarem parecidas com as outras. Em um olhar semiológico, a indumentária é texto. Pelas tramas dos tecidos leem-se múltiplos discursos que explicitam os anseios pessoais, a expressão de subjetividades, a influência da sociedade sobre o indivíduo e a sua postura política.

Barthes (2005, p.267) distinguiu dois conceitos: indumentária e traje. O primeiro fundamenta-se como construção social que vai além do indivíduo; já o segundo é individual, por se basear no ato de vestir-se no qual a pessoa apropria-se da indumentária para forjar sua aparência. Esta distinção nos remete aos conceitos semiológicos de língua e fala.

A indumentária aproxima-se da língua. É acima de tudo social. É o ser ligado ao todo por intermédio do que veste. Para Barthes (2006, p.19) a língua "[...] Trata-se essencialmente de um contrato coletivo ao qual temos de submeter-nos em bloco se quisermos comunicar; além disso, este produto social é autônomo [...], pois só se pode manejá-lo depois de uma aprendizagem [...]".

O traje nos remete à fala. Mostra-se na forma com que cada ser expressa sua aparência individualmente no contexto social: "[...] é essencialmente um ato individual de seleção e atualização"; já a fala constitui-se pelas "[...] combinações graças às quais o falante pode utilizar o código da língua com vistas a exprimir o pensamento pessoal" (BARTHES, 2006, p.18). Essa analogia com a esfera linguística refere-se essencialmente às questões ligadas ao papel da Moda, compreendida como um conjunto que se forma no entrecruzamento entre indumentária e traje.

O texto Neste Ano o Azul está na Moda (Barthes, 2005, p. 307-33) contém as chaves para se compreender as suas reflexões. Nele, mostra o quanto a publicidade produz conceitos artificiais, como, por exemplo, relacionar primavera à leveza e à suavidade de cores; inverno, à sobriedade e tons fechados. As revistas de moda estão repletas de afirmações do gênero: o vestido de corte ajustado que dá o toque sedutor ao look; bermudas ajustadas combinadas com camisetas deram o ar descontraído da coleção; a saia rodada que transpira romantismo, dentre outros clichês dos periódicos do ramo. Ou seja, o discurso das tendências de mercado busca naturalizar algo que nada tem de natural. Cria necessidades que levam o público a querer consumir as novidades descartando o que já possuem, mesmo que ainda estejam em condições de uso, pois é preciso ser descontraído, sóbrio ou romântico, de acordo com o que é lançado. 
A naturalização de um discurso forjado pela mídia transforma as roupas em objetos mitificados, ou seja, não são vistos como peças a serem simplesmente vestidas, mas sim um conjunto de elementos que tem o potencial de transformar seus usuários em algo mais: a sedutora; a que tem atitude; o descolado; o aventureiro, entre outros. Barthes retoma, de certa forma, alguns dos temas que havia estudado em Mitologias (2010), obra clássica na qual faz um estudo dos diversos mitos da sociedade burguesa e as suas táticas de convencimento.

Em Linguagem e Vestuário, publicado em 1959, o autor expressa aquilo que será o caminho para sua pesquisa futura. Afirma que a moda impressa, em um ponto de vista semiológico, "[...] funciona como uma verdadeira mitologia do vestuário [...] que, parece-me, deve ser a primeira etapa de uma linguística indumentária" (BARTHES, 2005, p.299). Nesse pequeno trecho, indica porque a Moda estava ausente de forma explícita em suas reflexões anteriores: fenômeno é tão importante, que ele dedicou um livro inteiro a ele, o Sistema da Moda (2009), no qual analisa com profundidade o vestuário, procurando entre os recortes do imenso patchwork social, encontrar, decodificar e ler os caminhos que as tramas dos fios podem engendrar.

\section{A HISTÓRIA SE POSICIONA}

A lacuna de um estudo sério e reflexivo sobre a História da Moda, levantada por Barthes em 1957, só foi preenchida na França por Fernand Braudel, em 1967, com a publicação da primeira versão do volume I de Civilização material, economia e capitalismo- séculos XV-XVIII: as estruturas do cotidiano, no qual há um capítulo intitulado Roupa e moda. Em 1979, o autor lançou a edição revisada da obra e os outros dois volumes: Os jogos das trocas e $O$ tempo e o mundo. Fernand Braudel foi um dos maiores expoentes da segunda geração dos Annales e professor do Collège de France a partir de 1949, onde gradativamente tornou-se uma espécie de norteador temático e metodológico para a historiografia francesa e mundial. Um dos principais focos de seu pensamento é o diálogo interdisciplinar entre a História e as Ciências Sociais, a partir da análise dos acontecimentos sob a ótica da longa duração; ou seja, a reflexão sobre os contextos históricos na esfera de uma temporalidade que ultrapasse o tempo breve dos episódios. Os fatos em si seriam como a ponta de um gigantesco iceberg que precisa de um mergulho profundo para que se tome a real dimensão de seu tamanho, extensão, escopo, ou melhor, duração.

Em seu texto, faz uma análise sobre a importância da indumentária do final da Idade Média até o século XVIII. Critica a futilidade das camadas abastadas; mas, em contrapartida vê a Moda com olhos bem otimistas. Para ele, a necessidade de mudanças rápidas nas vestes - devido à pressão dos imitadores e a busca de distinção por parte da aristocracia - gerar dinamização comercial, subida na escala social de grupos que antes jamais poderiam almejar um futuro diferente, progresso material e certa melhoria do bem-estar social. Logo, o estudo dessa área tão pouco valorizada pelos historiadores mostrava-se de fato necessário.

A história das roupas é menos anedótica do que parece. Levanta todos os problemas, os das matérias-primas, dos processos de fabrico, dos custos de produção, da fixidez cultural, das modas, das hierarquias sociais. Variado, o traje por toda a parte se obstina em denunciar as oposições sociais (BRAUDEL, 2005, p. 281). 
O trecho supracitado demonstra que o historiador francês não encara nas roupas somente as funções de adorno, vaidade, beleza e proteção. Ele as vê como algo que abarca o processo produtivo, as questões culturais, os modismos passageiros das aparências e, acima de tudo, os conflitos entre os grupos sociais, ou seja, a indumentária não pode jamais ser vista como um simples objeto isolado. Dessa forma, percebe-se que propõe uma espécie de modelo para aqueles que pretendem estudar o papel dos trajes na História: as formas vestimentares se remetem às estruturas e às disputas entre camadas sociais. Para se ter a real dimensão do vestuário dentro de uma sociedade ou época, é necessário relacioná-lo com a grande diversidade de elementos que o cercam. A questão central não são os vestidos, acessórios e combinações, mas as relações destes com tudo o que está ao seu redor. Braudel mostra que o estudo das roupas na História não pode ser encarado como uma simples descrição das diferentes silhuetas através do tempo, mas sim como um elemento da cultura material no qual se encontram entrecruzadas as questões econômicas, a mobilidade ou imobilidade dos grupos sociais e os valores culturais.

Em seu trabalho, encontra-se fortemente o binômio da imitação e distinção, amplamente discutido por sociólogos, como, por exemplo, Herbert Spencer (1883) e Georg Simmel (1911) na virada do século XIX para o XX. Em um trecho interessante de seu texto, apesar de afirmar que se tratam de exceções, não restringe a prática competitiva das aparências somente entre realeza, nobreza e burguesia; afirma que a roupa e os elementos dos modismos também atingem, em algumas poucas ocasiões alguns membros das camadas populares que possuem uma melhor condição financeira, logo os historiadores da indumentária não deveriam limitar-se ao estudo das elites.

\begin{abstract}
As leis suntuárias correspondem, portanto à sensatez dos governantes, mas mais ainda às inquietações das classes altas da sociedade quando se vêem imitadas pelos novos-ricos. Nem Henrique IV nem a sua nobreza poderiam consentir que as mulheres e as filhas da burguesia parisiense se vestissem de seda. Mas, nunca ninguém pode opor-se à paixão arrivista ou ao desejo de usar a roupa que, no Ocidente, é sinal de promoção social. [...] O mesmo se passa nos universos mais medíocres. Em Rumieges, aldeia de Flandres, perto de Valenciennes, em 1696, no dizer do cura, que escreve o seu diário, os camponeses ricos sacrificam tudo ao luxo do trajar, "os jovens andam de chapéus agaloados a ouro e prata [...]; as moças com penteados de um pé de altura e as outras vestimentas a condizer [...]". Mas é uma exceção, como o são, numa representação da festa do patrono de uma aldeia alemã, em 1680, umas camponesas de gola frisada. Habitualmente, andam todos descalços ou quase, e até mesmo no mercado de uma cidade basta uma olhadela para distinguir burgueses de gente do povo (BRAUDEL, 2005, p. 281).
\end{abstract}

Porém, de maneira muito bem-humorada, afirma que não haveria Moda se no mundo só houvesse pessoas de baixa poder aquisitivo:

\begin{abstract}
As leis suntuárias correspondem, portanto à sensatez dos governantes, mas Se assim o fosse, o problema nem sequer se apresentaria. Tudo permaneceria imóvel. Não haveria riqueza, nem liberdade de movimentos, nem mudanças possíveis. Os seus trajes, fossem feios ou bonitos, seriam sempre iguais. Bonito é o traje de festa, muitas vezes transmitido de pais para filhos e que, a despeito da infinita variedade dos trajes populares nacionais e regionais, se mantém ao longo dos séculos igual a si próprio. Feia é a roupa cotidiana de trabalho que utiliza os menos dispendiosos dos recursos locais e muda ainda menos do que o outro (BRAUDEL, 2005, p. 283).
\end{abstract}

Braudel estabelece uma diferenciação entre os termos roupa e Moda. O primeiro sempre existiu desde que os homens primitivos - por proteção, vaidade ou pudor - começaram a cobrir seus corpos. Já o segundo é uma prática que aparece no Ocidente 
europeu com o desenvolvimento comercial e urbano das cidades italianas na passagem da Idade Média para a Moderna, restringindo-se às camadas abastadas. Sua definição do conceito de Moda é bem significativa: "A moda é também a busca de uma nova linguagem para derrubar a antiga, uma maneira de cada geração renegar a precedente e distinguir-se dela [...]" (BRAUDEL, 2005, p. 293). Para ele, a Moda, além de se relacionar ao vestuário, encontra-se intimamente ligada às formas de comer, andar, saudar as pessoas, decorar suas habitações, entre outros elementos.

No entanto, afirma que o fenômeno não teve de seu surgimento, até o final do século XVII, uma abrangência maior. Crê que os ciclos de mudança foram ainda lentos; acredita que foi somente no XVIII, que a loucura e os caprichos obsessivos em relação às aparências tomaram conta do cotidiano da burguesia e da aristocracia. Este é um ponto bem questionável de seu texto. Pensar que a Moda, a partir do início do século XV, tornou-se algo insaciável em todos meios aristocráticos, com certeza, seria tão ingênuo quanto dizer que os ideais humanistas revolucionaram o cotidiano da maior parte da população europeia da mesma época. Porém, como analisar a corte de Henrique VIII deixando de lado o fato de que a influência de suas vestes nas aparências ultrapassava em muito os limites dos territórios que governava? Como não observar que a ostentação de seu poder e de sua virilidade por intermédio de suas roupas, fato muito bem representado nos retratos de Hans Holbein, marcou a época? Seria adequado pensar no reinado de Elizabeth I (1558 a 1603) sem perceber a força que as mudanças no vestuário da rainha exerceram na Inglaterra e em outros locais da Europa? Como refletir sobre a construção da imagem pública de Luís XIV, coroado em 1654, não levando em conta o fato de o monarca ter transformado Paris e, mais exatamente, a corte de Versalhes, em capital da Moda na Europa? Ao mesmo tempo, há uma passagem em que surge uma contradição, pois mostra presença intensa das mudanças das aparências entre os séculos XVI e XVII:

\begin{abstract}
Se compararmos, por exemplo, na Pinacoteca de Munique, um quadro de Pieter Aertsen (1508-1575) e duas telas de Jan Brueghel (1568-1625), todos os três representando o povo dos mercados, é bastante divertido verificar primeiro que, em todos os casos, se reconhecem à primeira vista os humildes vendedores ou pescadores e os grupos de burgueses [...], o traje diferencia-os imediatamente. Mas, a segunda constatação, mais curiosa, é que durante o quase meio século que separa os dois pintores, o traje burguês mudou muito [...], entretanto, o traje popular [...] manteve-se igual [...] (BRAUDEL, 2005, p. 284).
\end{abstract}

Outra importante constatação feita por ele é que a Moda, vista como um sistema regulado por mudanças constantes é um processo que pertence somente às sociedades ocidentais. No Oriente, entre os séculos XV e XVIII, existe uma riqueza enorme de trajes e elementos simbólicos que ostentam, porém não há mudanças contínuas em suas formas. Cita como exemplo a roupa do mandarim que, desde o século XIII até o XVIII, aparecem nas gravuras com as mesmas silhuetas, combinações e cores. Mesmo com as transformações ocorridas com as invasões tártaras no século XVII, poucas modificações aconteceram nas aparências: "Os novos senhores impuseram aos seus súditos os cabelos curtos (exceto um rabicho) e modificaram um pouco a grande túnica de outrora. Foi tudo: afinal, pouca coisa" (BRAUDEL, 2005, p. 282).

As colocações citadas no parágrafo anterior demonstram que nas sociedades orientais - China, Japão, Índia e Império Turco - citadas por Braudel em sua obra, não havia espaço para a existência da Moda. Nelas, o olhar constante para as posturas e valores herdados dos antepassados era expresso através de vestimentas, acessórios e 
gestos que mantinham vivas as tradições, ou seja, as relações de sociabilidade eram legitimadas pelo passado. A lógica das transformações constantes das formas do parecer só encontra espaço em locais onde há o privilégio pelo presente e a busca incessante pela novidade. Sobre o mundo oriental:

Mouradj d'Ohsson, no seu Tableau Géneral de l' Empire Ottoman, editado em 1741 , observa que "as modas que tiranizam as mulheres europeias não agitam o sexo no Oriente: lá quase todos andam com o mesmo penteado, o mesmo corte de roupa, o mesmo gênero de tecido" (BRAUDEL, 2005, p. 283).

Para o historiador francês, o estudo dos trajes revela-se duplamente importante. Em primeiro lugar, os materiais que compõem uma roupa, como tecidos, pedraria e corantes, contam toda uma história sobre quem os fabricou e em quais condições trabalharam. Logo, nos dão pistas importantes sobre toda a cadeia produtiva e as questões sociais nela envolvidas. Em segundo, porque nos descortina um amplo universo de posturas. "Esta moda que toca em tudo é a maneira como cada civilização se orienta. É tanto pensamento como o traje, a expressão do sucesso como o gesto de coquetterie, a maneira de receber à mesa, o cuidado ao fechar uma carta, é a maneira de falar [...]" (BRAUDEL, 2005, p.296).

O projeto inicial desta brilhante obra partiu nos anos 1950 de Lucien Febvre. Sua ideia era contar a História da Europa entre 1400 e 1800 em dois grandes volumes. Braudel trataria das questões ligadas à vida material e seu parceiro intelectual pesquisaria sobre os assuntos tocantes ao pensamento e às crenças. Febvre não teve tempo de escrever sua parte, pois faleceu em 1956. O autor deixou o livro de lado por alguns anos, todavia retornou a ele e assumiu a ambiciosa empreitada, porém pouca atenção reservou para os temas que seriam abordados por seu companheiro de estrada. O capítulo Roupa e Moda texto que se encontra no volume, traz contribuições geniais para o estudo do tema e, além disso, é um marco; pois, pela primeira vez, um historiador europeu lançou um olhar realmente reflexivo que rompeu com a superficialidade da simples narração da evolução das silhuetas.

O historiador francês Daniel Roche dedica-se, desde os anos 1970, ao estudo do consumo, dos trajes e da habitação. Duas de suas obras são de extrema relevância para o objeto aqui estudado: A cultura das aparências: uma história da indumentária (Séculos XVII-XVIII), publicada em 1989; e História das coisas banais - nascimento do consumo (séculos XVII-XIX), lançado em 1997. Para ele, os trajes são os primeiros veículos da passagem da civilização dos costumes para a civilização de corte ${ }^{2}$. A Moda sempre funcionou entre dois polos: a liberdade e a sujeição; entre o curvar-se à tendência dominante e à necessidade de expressão da individualidade. Portanto, seu estudo é primordial para a compreensão do intrincado jogo das aparências, nas mais diversas sociedades.

Em história das coisas banais: nascimento do consumo séc. XVII-XIX (2000), afirma que o estudo da cultura material como fonte histórica é essencial, pois permite aos pesquisadores estabelecerem ligações entre objetos que antes eram considerados irrelevantes, com as questões sociais, econômicas, religiosas e políticas. Todo artefato carrega em si uma história, seja ele um vestido, um quadro, uma xícara, um prato, entre outros. Os utensílios criam relações humanas que ultrapassam sua materialidade; funcionam não somente como códigos de comunicação e diferenciação social, mas ainda como elementos de uma rede de sensibilidades indispensáveis à compreensão da His2 ELIAS, Norbert. 0 processo civilizador, Volumes 1 e 2. RJ: Jorge Zahar Editor. 2008. Passim. 
tória. "Qualquer objeto, mesmo o mais comum, contém engenhosidade, escolhas, uma cultura" (DAGONET, Apud ROCHE, 2000, p.19).

\begin{abstract}
Um saber e um acréscimo de sentido estão ligados a todos os objetos. Vemos isso em seu modo de aquisição, no qual a moral, os princípios que os distinguem, as escolhas pessoais, intervêm na parte do orçamento a ele dedicado, na maneira de sua utilização em que se revelam um ensinamento e uma moral do uso nas normas e nas regras de decoro, no modo de sua posse em que a magnificência e o desperdício dos grandes contratam com o consumo ostentatório dos burgueses ou com o consumo compulsivo dos novos-ricos (ROCHE, 2000, p. 19).
\end{abstract}

Em A cultura das aparências (2007), reflete sobre o papel da indumentária na corte francesa do Antigo Regime. Aproximando-se de Roland Barthes (2006), considera que o vestuário é a relação entre dois níveis da realidade: o de vestir um traje como ato personalizado no qual o indivíduo se apropria dos padrões propostos, porém atribui à roupa elementos de gosto pessoal (fala); e o de vestir a indumentária, prática na qual a pessoa coloca sobre seu corpo aquilo que lhe é sancionado pela sociedade (língua). Para Roche

A moda situa-se no cruzamento do fato de vestir, que um indivíduo pode lançar e generalizar no sistema indumentário, em que ela se torna propriedade comum, com o fato de vestimenta, generalizada numa maneira de vestir e reproduzida em escala coletiva, na alta-costura, por exemplo. As mudanças podem ser compreendidas nessa relação, com o significado da roupa crescendo à medida que se passa do ato pessoal ao gesto comum. A relação entre o indivíduo vestido e a sociedade que propõe o código do vestir pode ser medida nas grandes mudanças, que afetam o sistema indumentário, e, por comparação, nas possibilidades de difusão e recepção (ROCHE, 2007, p. 59).

Em sua obra, ao analisar os trajes da corte francesa, encara a história das roupas por meio de dois caminhos: o da função das peças vestidas e o das transformações da sensibilidade. Afirma que, embora se vestir seja uma necessidade, o historiador não se pode deixar limitar por este viés, pois ficaria apenas na superfície das formas e estilos, não se permitindo mergulhar na complexa teia simbólica construída no universo das aparências. O vestuário indica inclusão e exclusão, hierarquia, imitação, distinção, gosto pessoal, entre diversos outros elementos, logo, é um caminho privilegiado para se ler a sociedade. A Moda expressa valores de sensibilidade e mobiliza sentidos. Através dos tecidos e suas cores, das folgas e apertos, pode-se perceber toda uma linguagem corporal de uma sociedade.

Para uma história da cultura indumentária da Idade Moderna, precisamos traçar a evolução das cores, dos contatos e do status dos tecidos. Como as aparências foram remodeladas será revelado por uma topologia corporal, por mudanças no que podia e não podia ser visto, por redefinições de modéstia e imodéstia e pelas lições de higiene que desafiaram os valores do asseio e do desasseio. As vestimentas modelam o corpo, e o corpo brinca de vestimenta; são meios de socialização, que têm seu rito de passagem. Entre a estabilidade e a mobilidade, as roupas descobrem a moda, que surge no campo das contradições sociais, quando existe uma possibilidade de desejar o que outros desejam (ROCHE, 2007, p. 47).

O cotidiano da sociedade de corte (ELIAS, 2001, passim) era permeado pela obrigatoriedade dos indivíduos em ser perdulários, por meio do exibicionismo, do luxo das roupas, festas, decoração, alimentação, entre outros. O gasto ostentatório era uma prática compulsória numa esfera social que priorizava a obrigação de esbanjar; uma camada na qual ser discreto ou econômico era quase que sinônimo de delito. Logo, a fu- 
tilidade da aristocracia que, para muitos pesquisadores, é um objeto menor nos estudos históricos, para Roche é uma das chaves para a compreensão daquele momento.

Ao se debruçar sobre o consumo e, em especial o dos artigos do universo da Moda, Roche indica que a ostentação do luxo expressa, ao mesmo tempo, o funcionamento das relações sociais e o questionamento das normas comportamentais estabelecidas pela sociedade. O aumento do espaço da burguesia - no mundo aristocrático europeu dos séculos XVIII e XIX, graças ao processo de industrialização e a difusão das ideias iluministas - gerou uma radical transformação nos padrões da cultura das aparências estabelecidos ao longo do Antigo Regime. O sistema indumentário burguês, a partir da Revolução Francesa e ao longo do século seguinte, desestabilizou as estruturas, estabelecendo novas formas para construção das silhuetas e das posturas. Percebe-se que, para o autor, a Moda vai muito além dos esquemas de imitação e distinção, típicos nas análises encontradas em várias pesquisas sobre o tema; ela funciona como um elemento de construção e desconstrução de significados. Mesmo com a Restauração promovida pelo Congresso de Viena em 1815 ou a existência de monarquias que desejavam resgatar a sociedade de corte, o mundo das aparências nunca mais foi o mesmo.

\section{O BRASIL ENTRA EM CENA}

Antes do início do século XX, o vestuário não foi objeto de estudo de estudo histórico em território nacional. As publicações sobre o tema estavam restritas aos manuais de etiqueta, aos jornais femininos e aos romances, como os de Machado de Assis, Joaquim Manuel de Macedo e José de Alencar. O primeiro livro dedicado à história da indumentária produzida no Brasil foi Três Séculos de Moda no Brasil, de João Afonso. O volume, escrito e ilustrado em 1915, foi encomendado pelo governo de Belém, como parte das comemorações do tricentenário da cidade (1616-1916), mas por questões de orçamento só foi publicado em 1923. Seu autor não tinha formação acadêmica, porém se tratava de um homem muito culto, dedicado a escrever em jornais sobre os mais diversos assuntos, o que fez com que ganhasse o status de intelectual no norte brasileiro. Não se trata de um texto acadêmico, mas de uma sucessão de descrições sobre a evolução das silhuetas das cortes europeias, em especial a francesa, e de que maneiras influenciaram as formas dos trajes em nosso território, sobretudo, em Belém.

O primeiro pesquisador que abordou o vestuário de uma forma reflexiva e problematizadora foi Gilberto Freyre. Nas obras, Sobrados e mucambos, de 1936 e, bem mais tarde, Modos de homem \& modas de mulher, de 1987, a indumentária aparece como um dos importantes elementos para o estudo da sociedade brasileira. No primeiro trabalho, a roupa ganha destaque nos momentos em que o autor discorre sobre os processos de assimilação dos trajes europeus, em especial no Segundo Reinado. Partindo dos relatos de viajantes e de estudos oriundos da medicina, indica a falta de adequação de tais siIhuetas e materiais em território brasileiro, como espartilhos, vestidos longos e pesados, uso da lã e do veludo que eram trajados em pleno verão tropical. A comparação entre as vestimentas femininas e masculinas a partir da posição que cada sexo ocupava na sociedade e também das formas de trajar das mulheres das camadas abastadas em público - impecáveis nas roupas e na postura - e no interior do espaço doméstico - totalmente largadas - fornecem questões de grande relevância para os estudos de gênero. Cinco décadas mais tarde, o sociólogo compila diversos artigos e publica a coletânea Modos 
de homem \& modas de mulher em 1987. Além de retomar as questões do livro dos anos 1930, discute os padrões de beleza da década de 1980, arquitetura, decoração e questões ecológicas. Ao confrontar as posturas entre os dois sexos, confere ao campo das mulheres as questões da moda, pois vê na personalidade feminina, construída socialmente, a preocupação com a beleza, com a ornamentação das formas e com a vaidade. Já ao campo do masculino, confere o modo; nos homens há a preocupação de serem educados e finos, de apresentarem bons modos, mas no vestir são discretos e sóbrios. Seus argumentos, embora hoje possam ser questionados, expressam muito bem a lógica das aparências construída pela burguesia em ascensão no século XIX.

Em 1950, Gilda de Mello e Souza, sob a orientação de Roger Bastide, apresentou a tese de doutoramento $A$ moda no século XIX: ensaio de sociologia estética. O trabaIho foi publicado no mesmo ano, na Revista do Museu Paulista, recebendo apreciações negativas da comunidade acadêmica. O sociólogo Florestan Fernandes publicou uma resenha na qual teceu alguns elogios à autora, porém também a criticou de forma dura:

\begin{abstract}
Tal como se apresenta, o trabalho da Dra. Gilda de Mello e Souza, revela duas coisas. Primeiro: o talento e a extraordinária sensibilidade da autora para a investigação de um fenômeno tão complexo, por causa das diversas facetas de que pode ser encarado e explicado. Segundo, um seguro conhecimento do campo de sua especialização, em um nível que até pouco tempo era raro no Brasil. Essas qualidades se refletem na composição do trabalho, tornando a sua leitura muito amena. Poder-se-ia, porém lamentar a exploração abusiva da liberdade de expressão (a qual não se coaduna com a natureza de um ensaio sociológico) e a falta de fundamentação empírica de algumas das explanações mais sugestivas e importantes. De outro lado, não concordamos com a afirmação da autora, segundo a qual "a moda, como toda manifestação do gosto, é traiçoeira e, quando analisada de perto, esconde suas feições mais características, induzindo o observador a erro" (p.10). A esse respeito, pensamos que uma das vantagens da abordagem sociológica do fenômeno consiste exatamente na possibilidade de compreendê-lo e interpretá-lo, através de técnicas de investigação adequadas, em suas manifestações no mundo em que vivemos, ou seja, como dimensões atuais do acontecer (FERNANDES, 1952, p. 139-140).
\end{abstract}

A tese somente alcançou um público maior ao ser lançada como livro em 1987, sob o título O espírito das roupas: a moda no século XIX. A pesquisa é de fundamental importância para a historiografia da Moda no Brasil, principalmente, por ser o primeiro estudo acadêmico nacional totalmente dedicado ao objeto. A inovação e a ousadia da autora se mostraram tão grandes naquele contexto, que fez com seu trabalho fosse considerado como "uma espécie de desvio em relação às normas predominantes nas teses da Universidade de São Paulo" (MELLO E SOUZA, 1993, p.7). Em seus capítulos, analisa a indumentária por meio das formas, dos tecidos, das cores, das relações de sociabilidade, da distinção social, das representações artísticas e dos estudos de gênero. Realiza um levantamento bibliográfico sobre a área que vai desde a Sociologia - Spencer, Veblen e Simmel - ao campo da literatura, por meio de referências aos textos de Balzac, Proust, Machado de Assis e José de Alencar. A estudiosa demonstra uma grande erudição, não somente por trabalhar com autores e temas tão diversos, mas também por estabelecer articulações entre eles e as transformações das roupas ao longo do século XIX. Apesar de a obra carecer de um recorte temático - a pesquisadora aborda diversas questões, todavia não deixa clara uma delimitação de objeto - trata-se de uma leitura obrigatória por trazer um olhar inédito ao assunto dentro da historiografia brasileira.

Em 1978, Maria Beatriz Nizza da Silva, lançou o livro Cultura e sociedade no Rio de Janeiro (1808-1821). Por meio de um profundo estudo de matérias publicadas na 
Gazeta do Rio de Janeiro, a historiadora traçou um perfil amplo, porém de forma alguma superficial, sobre as práticas cotidianas durante o Período Joanino: moradias, festas, cerimônias, arte, escravidão e vestuário são alguns dos temas abordados sobre uma época de grandes transformações na cidade do Rio de Janeiro. A Moda tem no livro uma grande relevância, principalmente, pelo cuidado da autora em explicitar que os trajes representam o lugar do indivíduo dentro do intrincado universo das relações sociais e que, por essa razão, as vestimentas, carregadas de simbolismos, geram naqueles que as portam uma série de posturas, gestos e vocabulário específico.

Em 2002, Maria do Carmo Teixeira Rainho publicou sua dissertação de mestrado, defendida dez anos antes, A cidade e a moda: novas pretensões, novas distinções - Rio de Janeiro, século XIX. Neste livro, a autora desenha um belíssimo painel sobre as relações entre as transformações do espaço urbano da capital brasileira, em especial no Segundo Reinado, e a apropriação da Moda europeia pela camada social que define como a boa sociedade:

[...] no âmbito deste trabalho, estamos qualificando os membros da "boa sociedade" como os homens e as mulheres que civilizaram seus costumes e fizeram da moda um elemento que acentuava as diferenças existentes entre eles próprios e entre eles e os outros estratos da população. São os homens e as mulheres que, ao europeizar seus corpos, passaram a preocupar-se com a correção do vestuário, com o vestir racional e com a adoção de roupas adequadas à posição que ocupavam na sociedade. São, enfim, aqueles que, por meio da aparência e não apenas do dinheiro e do poder, deixavam visíveis as diferenças que marcavam o abismo existente entre a "boa sociedade" e a "sociedade comum" [...] (RAINHO, 2002, p. 17).

A obra é o resultado de uma intensa e inédita pesquisa a partir do estudo de três tipos de fontes: os manuais de civilidade, como, Entretenimentos sobre os deveres de civilidade colecionados para o uso da puerícia brasileira de ambos os sexos (1875) e Escola de política ou tratado prático da civilidade portuguesa (1845); os periódicos de Moda ou que possuíam seções dedicadas a ela, como O novo correio das modas (1852-1855), 0 jornal das senhoras (1852-1855), A marmota fluminense (1852-1857), A mãe de família (1879-1888) e O sexo feminino (1873-1889); além de teses apresentadas à Faculdade de Medicina do Rio e Janeiro, como por exemplo, Considerações acerca da idade crítica da mulher (1849), Algumas considerações acerca das vestimentas (1849), Da educação Física, intelectual e moral da mocidade do Rio de Janeiro e de sua influência sobre a saúde (1855) e Algumas reflexões sobre a cópula, O nanismo e prostituição (1855).

Partindo de fontes extremamente diversas, a pesquisadora teceu uma ampla teia sobre as múltiplas representações da Moda através dos diversos discursos que a estruturavam, mostrando como a boa sociedade incorporava os elementos europeus e, ao mesmo tempo, procuravam estabelecer a sua visão de mundo, valores de certo e errado; em suma, impor o que consideravam como pertencentes à civilização. A partir de fontes de origens muito diferentes, mas que dialogavam entre si, Rainho costurou um panorama da sociedade do Rio de Janeiro por meio da Moda.

Vale aqui destacar a distância temporal entre as pesquisas nacionais supracitadas: Gilberto Freyre (1936), Gilda de Mello de Souza (1950), Maria Beatriz Nizza da Silva (1978) e Maria do Carmo Teixeira Rainho (2002). Esta observação deixa bem clara as grandes lacunas de décadas entre as publicações, o que expressa o desinteresse que tomava conta dos pesquisadores e do mercado editorial sobre o tema. 
Apesar de ainda ser tímida, a produção acadêmica na área de História da Moda, em território nacional, passou por uma grande ampliação nos últimos quinze anos. Publicações de grande peso foram feitas, como por exemplo: Camila Borges da Silva - O símbolo indumentário: distinção e prestígio no Rio de Janeiro - 1808-1821 (2010); Geanneti Tavares Salomon - Moda e ironia em Dom Casmurro (2010); Rosane Feijão - Moda e modernidade na Belle Époque Carioca (2011); Maria Claúdia Bonadio e Maria de Fátima Mattos (org.) - História e cultura de moda (2011); Marcelo de Araújo - Dom Pedro II e a moda masculina na Época Vitoriana (2012); Maria Cláudia Bonadio - Moda e publicidade no Brasil nos anos 1960 (2014), Maria do Carmo Teixeira Rainho - Moda e revolução nos anos 1960 (2014); Mara Rúbia Sant'Anna - Sociabilidades Coloniais Entre o Ver e o Ser Visto (2017); Maria Cristina Volpi - Estilo Urbano. Modos de Vestir na Primeira Metade do Século XX no Rio de Janeiro (2018), Laura Ferraza de Lima - Quando a Arte encontra a Moda (2018) e Joana Monteleone, Camila Borges e Paulo Debom (org.) - A História na Moda, a Moda na História (2019).

Em 2005, foi realizado o Primeiro Colóquio de Moda, organizado pela Associação brasileira de estudos e pesquisa em Moda (ABEPEM), no qual professores e pesquisadores de Moda de diversas universidades promoveram um encontro nacional de caráter acadêmico sobre o tema. $O$ início foi bem modesto, porém gradativamente o evento cresceu e ganhou visibilidade internacional. Há vários simpósios com temáticas variadas e, no terceiro ano, teve início o simpósio temático História e Cultura das Aparências. Em 2010, passou a ser denominado Moda, Cultura e Historicidade, em que são apresentados e discutidos trabalhos oriundos das mais variadas universidades brasileiras. Vale destacar que se trata de um evento de profissionais de Moda, no qual participam sociólogos, psicólogos, historiadores, publicitários, designers, empresários, fotógrafos, entre outros e, que dentro dele foi aberto um espaço para um GT (grupo de estudos) dedicado à História.

Em 2007, foi lançado, no encontro da Associação Nacional de História (ANPUH Brasil), um simpósio sobre Moda, porém a iniciativa pioneira não foi à frente por falta do número suficiente de inscritos. Dentre os eventos organizados especificamente na área de História, o primeiro a contemplar um espaço dedicado à História da Moda foi a Semana de História Política do PPGH-UERJ, em 2011, com o simpósio Temático Moda, Imagem \& Poder. Em 2013, o Congresso Internacional de História do PPH-UEM também se abriu para o tema com o simpósio intitulado História das Roupas, da Moda e dos Gêneros. Entre 2012 e 2019, a Casa de Rui Barbosa no Rio de Janeiro promoveu encontros dedicados à área. As edições nacionais da Anpuh Brasil em 2017 e 2019 contaram com o simpósio Por uma compreensão histórica das aparências: os usos da moda, do vestuário e da visualidade. Percebe-se que os preconceitos estão gradativamente diminuindo e, com isso, a produção nacional enriquecendo. Diante desse cenário, nota-se que a Moda e o vestuário conseguiram realmente se estabelecer enquanto objetos de estudo e pesquisa no cenário brasileiro.

\section{REFERÊNCIAS}

AFFONSO, João. Três séculos de modas. Belém: Conselho estadual de Cultura, 1976. 
BARTHES, Roland. Inéditos 3: Imagem e Moda. São Paulo: editora Martins Fontes, 2005.

Sistema da Moda. São Paulo: editora Martins Fontes, 2008.

Elementos de Semiologia. São Paulo: editora Cultrix, 2006.

Mitologias. Rio de Janeiro: editora Difel, 2010.

BRAUDEL, Fernand. Civilização Material, Economia e Capitalismo - Séculos XV-XVIII: As Estruturas do Cotidiano. Volume 1. São Paulo: editora Martins Fontes, 2005.

ELIAS, Norbert. A Sociedade de Corte. Rio de Janeiro: Jorge Zahar Editor, 2001.

FREYRE, Gilberto. Modos de homem e modas de mulher. Rio de Janeiro: Record, 1986.

Sobrados e mucambos. Rio de Janeiro: José Olympio, 1985.

RAINHO, Maria do Carmo Teixeira. A cidade e a moda: novas pretensões, novas distinções - Rio de Janeiro - Século XIX. Brasília: UNB editora, 2002.

ROCHE, Daniel. História das Coisas Banais: nascimento do consumo (séc. XVII-XIX). Rio de Janeiro: editora Rocco, 2000.

A Cultura das Aparências: Uma História da Indumentária (séculos XVII-XVIII). São Paulo: editora SENAC, 2007.

SILVA, Maria Beatriz Nizza da. Cultura e sociedade no Rio de Janeiro (1808-1821). Rio de Janeiro: editora Nacional, 1978.

SOUZA, Gilda de Mello e. O espírito das roupas: a moda no século XIX. São Paulo: Companhia das letras, 1993.

Recebido em: 12/08/2019

Aceito em: 09/09/2019

DOI: http://dx.doi.org/10.5965/25944630332019013 